\title{
Profile of Aerobic Bacteria in Surgical Site Infection Following Caesarean Section and Antibiotic Susceptibility Pattern in Silchar Medical College, India
}

\author{
Nazrana Choudhury ${ }^{1}$, Abul Barkat Fuzayel Ahmed ${ }^{2}$, Debadatta Dhar Chanda ${ }^{3}$, Achinta Kumar Borthakur ${ }^{4}$ \\ 1, 3, 4 Department of Microbiology, Silchar Medical College, Cachar, Assam, India. \\ ${ }^{2}$ Department of Obstetrics and Gynaecology, Silchar Medical College, Cachar, Assam, India.
}

\section{ABSTRACT}

\section{BACKGROUND}

Caesarean section is one of the most common surgeries performed in women of reproductive age group. Postoperative surgical site infection (SSI) is the third most frequently reported nosocomial infection. Recovery after caesarean section can be more demanding for a woman who develops a post-operative surgical site infection that can even lead to death. Surveillance of surgical site infection is an important infection control activity. A better understanding of the spectrum of pathogens causing SSI as well as their susceptibility pattern is important for prompt management of patients. The main objectives of this study were to identify the bacterial agents causing postoperative wound infection in caesarean section, as well as determine the in-vitro antimicrobial susceptibility pattern of different bacterial isolates and also to examine the risk factors of postoperative caesarean infection.

\section{METHODS}

This is an observational (cross sectional study) where 100 cases of postoperative caesarean section wound infection admitted in the Department of Obstetrics \& Gynaecology, Silchar Medical College were studied. Pus samples were collected and cultured, and the pathogenic isolates were tested against different antimicrobial agents by standard disc diffusion method (Kirby-Bauer method) as per the recommendation of Clinical and Laboratory Standard Institute (CLSI) guidelines.

\section{RESULTS}

The study revealed Staphylococcus aureus $38.1 \%$ of which $21.9 \%$ were methicillin resistant (MRSA), as the most common organism responsible for SSI followed by Escherichia coli $23.8 \%$ and Klebsiella pneumoniae $16.7 \%$. Staphylococcus aureus was $100 \%$ sensitive to vancomycin and linezolid $78.1 \%$ and $71.9 \%$ sensitive to erythromycin and ciprofloxacin respectively. The most sensitive antimicrobials for Gram negative isolates were polymyxin B $96.2 \%$, imipenem $94.2 \%$ and ciprofloxacin $76.9 \%$. Emergency C-section (83\%), premature rupture of membranes (PROM) 30 $\%$, prolong labour $26 \%$, history of previous caesarean section $22 \%$, anaemia $15 \%$ cases and $\mathrm{BMI} \geq 25(16 \%)$ were found to be risk factors.

\section{CONCLUSIONS}

The findings of preponderance of Staphylococcus aureus and Gram negative bacilli in this study with good antibiotic sensitivity against the fluoroquinolone and aminoglycosides is of local clinical relevance.

\section{KEY WORDS}

Caesarean Section, Surgical Site Infection, Antimicrobial Susceptibility Pattern, Bacterial Isolates, MRSA Strains
Corresponding Author: Dr. A.B. Fuzayel Ahmed, Department of Obstetrics And Gynaecology, Silchar Medical College, Cachar-788014, Assam, India. E-mail:drfuzayel@rediffmail.com

DOI: $10.14260 /$ jemds/2021/618

How to Cite This Article:

Choudhury N, Ahmed ABF, Chanda DD, et al. Profile of aerobic bacteria in surgical site infection following caesarean section and antibiotic susceptibility pattern in Silchar medical college, India. J Evolution Med Dent Sci 2021;10(35):3030-3034, DOI: 10.14260/jemds/2021/618

Submission 05-11-2020, Peer Review 28-01-2021, Acceptance 04-02-2021, Published 30-08-2021.

Copyright (C) 2021 Nazrana Choudhury et al. This is an open access article distributed under Creative Commons Attribution License [Attribution 4.0 International (CC $B Y 4.0)]$ 


\section{BACKGROUND}

Caesarean section is one of the most common surgeries performed in women of reproductive age group. ${ }^{1}$ The incidence of caesarean section is increasing worldwide. Caesarean section rate in 2007 reached $32 \%$ in US, a $50 \%$ increase since 1996. Repeat caesarean section rate is estimated as $92 \% .^{2}$ In India incidence is estimated to be about $32-60 \%{ }^{3}$ Increase in caesarean section rate has contributed to increased incidence of wound morbidity. Recovery after Caesarean section can be more demanding for women who develop post-operative surgical site infection that can even lead to death. ${ }^{4}$ Surgical site infection is a type of healthcareassociated infection. It limits the potential benefit of surgical procedures. Surgical site infection (SSI) is defined as an infection occurring within 30 days after surgical operation (or within 1 year if an implant is left in place after the procedure) and affecting either incision or deep tissues at the operation site. $^{5}$ According to National Nosocomial Infections Surveillance (NNIS) system postoperative surgical site infection is the third most frequently reported nosocomial infection accounting for $14-16 \%$ of all infections in the hospitalized patients ${ }^{5}$ and is associated with increased morbidity, mortality, prolonged hospital stay and increased economic costs for patient care. ${ }^{6} \mathrm{~A}$ number of predisposing factors are found to be associated with caesarean section infection. Preoperatively a number of patient related factors like anaemia, diabetes mellitus, premature rupture of membranes, body mass index (BMI) > 25 etc. have been associated with the increased risk of SSI. ${ }^{7}$ The infection may be acquired during the operation itself either exogenously from air, medical equipment's, instruments etc. or endogenously from the flora of the skin and operative site. There has been advances in surgical site infection control practices which include better sterilization methods, surgical techniques and availability of antimicrobial prophylaxis. Despite these, surgical site infections remain as one of the common causes of morbidity and mortality due to emergence of antimicrobial resistant pathogenic bacteria. ${ }^{3}$ Microbial etiological agents, some alone and some in combination (polymicrobial) are known which include Staphylococcus aureus, Escherichia coli, klebsiella species, pseudomonas species etc. ${ }^{8}$ According to data from the NNIS system, the distribution of pathogens isolated from SSIs has not changed markedly during the last decade. Staphylococcus aureus, coagulase-negative staphylococci, Escherichia coli remain the most frequently isolated pathogens. An increasing proportion of SSIs is caused by antimicrobial-resistant pathogens, such as methicillinresistant S. aureus (MRSA). ${ }^{5}$ The sensitivity pattern of post caesarean section surgical site infection isolate is changing due to increasing emergence of these antimicrobial resistant pathogenic bacteria making the choice of empirical treatment more difficult and expensive. ${ }^{9}$ As most of the studies on SSI in C-section patients have been conducted outside India, not much data is available on its incidence rate in Indian hospitals. Data is also lacking in the knowledge of common pathogens causing SSI in caesarean section in Indian hospitals. ${ }^{7}$ Surveillance of surgical site infection is an important infection control activity. Therefore, a better understanding of the spectrum of pathogens causing SSI as well as their susceptibility pattern is important for prompt management of patients, as antimicrobial therapy significantly influences the outcome of the patient with SSI following caesarean section. Considering all these the present study was undertaken.

\section{METHODS}

This is an observational cross-sectional study, and the study period was one year from September 2014 to August 2015 during which 100 cases of postoperative caesarean section wound infection were randomly selected from the Department of Obstetrics \& Gynaecology, Silchar medical college, Assam. Patients who developed post-operative caesarean section wound infections were included in the study. Infections were identified during hospital stay or within 30 days of caesarean section by readmission to the hospital and was defined on the basis of CDC criteria of defining surgical site infection. ${ }^{5}$ Patients having localized stitch abscess were excluded from this study.

Pus swabs were collected from the site of caesarean wound infection using sterile cotton wool swab, or was aspirated out with a sterile syringe carefully avoiding contamination from skin or other site and tested in the Bacteriology laboratory of the Department of Microbiology in Silchar Medical College \& Hospital, Silchar. Gram stain of the collected specimens was performed.

The collected pus samples were seeded on to Blood Agar, MacConkey Agar and Nutrient Agar medium and streak culture was done. The plates were then incubated aerobically at $37^{\circ} \mathrm{C}$ for up to 48 hours before considering sterile. If there was growth, isolates were identified by the colony characteristics, Gram staining, motility of organisms and biochemical reactions. All of the isolated pathogenic bacterias were tested against different antimicrobial agents by standard disc diffusion method (kirby-bauer method) as per recommendation of Clinical and Laboratory Standard Institute (CLSI) guidelines. ${ }^{10}$

After overnight incubation at $37^{\circ} \mathrm{C}$ the zone of inhibition around each antibiotic disc was measured to the nearest millimetre, which included the diameter of the disc. The results were interpreted by using the zone size interpretative chart provided by the manufacturers of the discs. Methicillin resistance was detected by cefoxitin $(30 \mu \mathrm{g})$. Staphylococcus aureus-ATCC 25923; Escherichia coli-ATCC 25922 and Pseudomonas aeruginosa-ATCC 27853 were used as control strains for AST.

\section{RESULTS}

Out of 100 cases of SSI that were studied, $22(22 \%)$ cases had history of previous Caesarean section, 26 (26\%) had prolong labour, 30 (30\%) had premature rupture of membrane, 83 (83 $\%$ ) cases were done on an emergency basis whereas only 17 (17\%) cases were done as elective surgery.

\begin{tabular}{|cccc|}
\hline Indications & Status & No. of Cases & Percentage \\
Previous caesarean section & Yes & 22 & $22 \%$ \\
& No & 78 & $78 \%$ \\
Prolong labour $\geq 12$ hours & Yes & 26 & $26 \%$ \\
& No & 74 & $74 \%$ \\
PROM & Yes & 30 & $30 \%$ \\
& No & 70 & $70 \%$ \\
\hline Table 1. Indications of Caesarean Section as Risk Factors of SSI \\
\hline
\end{tabular}


$02(02 \%)$ of patients of SSI were diabetic, $15(15 \%)$ patients had anaemia, 16 (16\%) patients had BMI 25 or more and 09 (09\%) patients were hypertensive. Out of 100 cases 72 revealed organisms in direct microscopy. In direct Gram stain maximum 26 (36.1\%) cases yielded Gram negative bacilli, followed by Gram positive cocci in clusters 25 (34.7\%). Gram negative coccobacilli in $11(15.3 \%)$ cases, Gram negative cocci in $03(4.2 \%)$ cases while 07 (9.7\%) cases showed mixed morphology. Out of 100 swabs cultured 74 (74\%) yielded bacterial growth. Out of 74 positive cultures, 64 (86.5\%) were monomicrobial yielding only one microorganism while 10 $(13.5 \%)$ were polymicrobial growth yielding two microorganisms at the same time. Therefore, a total of 84 bacterial isolates were obtained.

\begin{tabular}{|c|c|c|c|}
\hline Isolates & Organism & $\begin{array}{l}\text { No. of } \\
\text { Cases }\end{array}$ & Percentage \\
\hline Gram positive cocci & Staphylococcus aureus & 32 & $38.1 \%$ \\
\hline Gram positive bacilli & -- & -- & -- \\
\hline Gram negative cocci & Acinetobacter baumannii & 04 & $4.76 \%$ \\
\hline \multirow{5}{*}{$\begin{array}{l}\text { Gram negative coccobacilli } \\
\text { Gram negative bacilli }\end{array}$} & Klebsiella pneumoniae & 14 & $16.7 \%$ \\
\hline & E. coli & 20 & $23.8 \%$ \\
\hline & Pseudomonas aeruginosa & 08 & $9.5 \%$ \\
\hline & Citrobacter freundii & 04 & $4.76 \%$ \\
\hline & Proteus vulgaris & 02 & $2.38 \%$ \\
\hline \multicolumn{2}{|c|}{ Total } & 84 & $100 \%$ \\
\hline \multicolumn{4}{|c|}{ Table 2. Isolation of Organisms from Culture } \\
\hline
\end{tabular}

Predominant organism isolated was Staphylococcus aureus 32 (38.1 \%) followed by Escherichia coli 20 (23.8\%). Other organisms isolated were Klebsiella pneumoniae 14 (16.7\%), Pseudomonas aeruginosa 8 (9.5\%), Acinetobacter baumannii 4 (4.76\%), Citrobacter freundii 4 (4.76\%) and Proteus vulgaris $2(2.38 \%)$.
Out of 32 isolated Staphylococcus aureus 25 (78.1\%) were MSSA strains while 7 (21.9\%) were MRSA strains. Among these 25 MSSA strains 23 (92 \%) were sensitive to ciprofloxacin, $20(80 \%)$ were sensitive to third generation cephalosporin (ceftriaxone and cefotaxime) and 19 (76\%) were sensitive to aminoglycosides (amikacin \& gentamycin). While among 7 isolates of MRSA strains 2 (28.6\%) were sensitive to ciprofloxacin and aminoglycosides (amikacin \& gentamycin) each. None (0\%) were sensitive to third generation cephalosporin (ceftriaxone and cefotaxime).

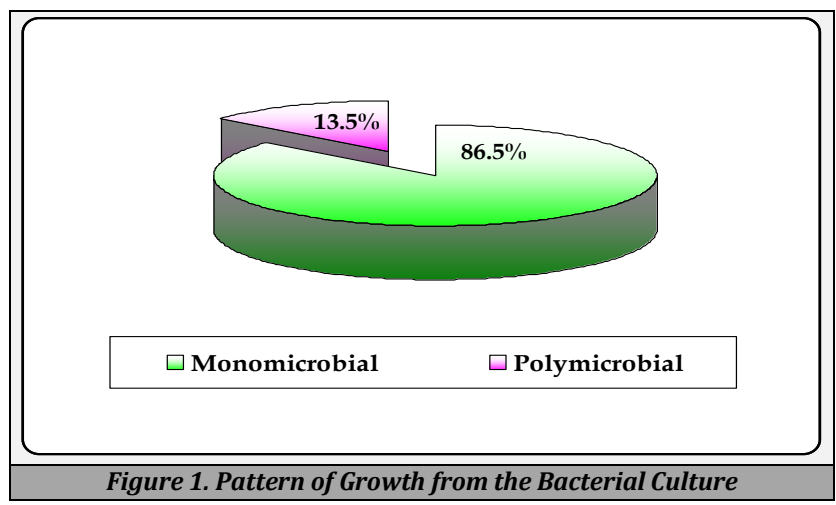

The most effective antimicrobial agent against the entire spectrum of Gram-negative bacilli isolated was polymyxin B showing $96.2 \%$ sensitivity. It was followed by imipenem 94.2 $\%$. Gentamycin and ciprofloxacin showed sensitivity of $76.9 \%$ each. However, ampicillin came out to be least sensitive $9.6 \%$.

\begin{tabular}{|c|c|c|c|c|c|c|c|c|c|c|c|c|c|}
\hline \multirow{2}{*}{ Isolates } & \multirow{2}{*}{ No. } & \multicolumn{12}{|c|}{ Number of Isolates Sensitive to Antimicrobials } \\
\hline & & A & AMC & GEN & AK & $\mathbf{E}$ & CLD & CIP & CTX & CTR & $\mathbf{C X}$ & VAN & $\mathbf{L Z}$ \\
\hline $\begin{array}{l}\text { S. aureus } \\
\text { MSSA }\end{array}$ & 25 & $\begin{array}{c}10 \\
(40 \%)\end{array}$ & $\begin{array}{c}16 \\
(64 \%)\end{array}$ & $\begin{array}{c}19 \\
(76 \%)\end{array}$ & $\begin{array}{c}19 \\
(76 \%)\end{array}$ & $\begin{array}{c}22 \\
(88 \%)\end{array}$ & $\begin{array}{c}12 \\
(48 \%)\end{array}$ & $\begin{array}{c}23 \\
(92 \%)\end{array}$ & $\begin{array}{c}20 \\
(80 \%)\end{array}$ & $\begin{array}{c}20 \\
(80 \%)\end{array}$ & $\begin{array}{c}25 \\
(100 \%)\end{array}$ & $\begin{array}{c}25 \\
(100 \%)\end{array}$ & $\begin{array}{c}25 \\
(100 \%)\end{array}$ \\
\hline $\begin{array}{l}\text { S. aureus } \\
\text { MRSA }\end{array}$ & 7 & $\begin{array}{c}0 \\
(0 \%)\end{array}$ & $\begin{array}{c}0 \\
(0 \%)\end{array}$ & $\begin{array}{c}2 \\
(28.6 \%)\end{array}$ & $\begin{array}{c}2 \\
(28.6 \%)\end{array}$ & $\begin{array}{c}3 \\
(42.9 \%)\end{array}$ & $\begin{array}{c}0 \\
(0 \%)\end{array}$ & $\begin{array}{c}2 \\
(28.6 \%)\end{array}$ & $\begin{array}{c}0 \\
(0 \%)\end{array}$ & $\begin{array}{c}0 \\
(0 \%)\end{array}$ & $\begin{array}{c}0 \\
(0 \%)\end{array}$ & $\begin{array}{c}7 \\
(100 \%)\end{array}$ & $\begin{array}{c}7 \\
(100 \%)\end{array}$ \\
\hline Total & 32 & $\begin{array}{c}10(31.25 \\
\%)\end{array}$ & $16(50 \%)$ & $\begin{array}{c}21 \\
(65.6 \%)\end{array}$ & $\begin{array}{c}21 \\
(65.6 \%)\end{array}$ & $\begin{array}{c}25 \\
(78.1 \%)\end{array}$ & $\begin{array}{c}12 \\
(37.5 \%)\end{array}$ & $\begin{array}{c}23 \\
(71.9 \%)\end{array}$ & $\begin{array}{c}20 \\
(62.5 \%)\end{array}$ & $\begin{array}{c}20 \\
(62.5 \%)\end{array}$ & $\begin{array}{c}25 \\
\text { (78.1 \%) }\end{array}$ & $\begin{array}{c}32 \\
(100 \%)\end{array}$ & $\begin{array}{c}32 \\
(100 \%)\end{array}$ \\
\hline
\end{tabular}

\begin{tabular}{|c|c|c|c|c|c|c|c|c|c|c|}
\hline \multirow{2}{*}{ Isolates } & \multicolumn{10}{|c|}{ Number of Isolates Sensitive to Antimicrobials } \\
\hline & $\mathbf{A}$ & AMC & PIP / T & AK & GE N & CIP & CTX & CTR & I & POLB \\
\hline E. coli $(20)$ & $\begin{array}{c}02(10 \\
\%)\end{array}$ & $13(65 \%)$ & $16(80 \%)$ & $14(70 \%)$ & $16(80 \%)$ & $18(90 \%)$ & $16(80 \%)$ & $16(80 \%)$ & $20(100 \%)$ & $20(100 \%)$ \\
\hline Klebsiella pneumoniae (14) & NT & $10(71.4 \%)$ & $08(57.1 \%)$ & $09(64.3 \%)$ & $10(71.4 \%)$ & $12(85.7 \%)$ & $09(64.3 \%)$ & $09(64.3 \%)$ & $13(92.9 \%)$ & $14(100 \%)$ \\
\hline Pseudomonas aeruginosa (8) & $\begin{array}{c}02(25 \\
\%)\end{array}$ & NT & $02(25 \%)$ & $07(87.5 \%)$ & $07(87.5 \%)$ & $05(62.5 \%)$ & NT & NT & $07(87.5 \%)$ & $08(100 \%)$ \\
\hline Acinetobacter baumannii (4) & $\begin{array}{c}01(25 \\
\%)\end{array}$ & NT & $01(25 \%)$ & $02(50 \%)$ & $02(50 \%)$ & $03(75 \%)$ & $01(25 \%)$ & $02(50 \%)$ & $03(75 \%)$ & $04(100 \%)$ \\
\hline Citrobacter freundii (4) & NT & NT & $02(50 \%)$ & $03(75 \% 0$ & $03(75 \%)$ & $01(25 \%)$ & $00(00 \%)$ & $00(00 \%)$ & $04(100 \%)$ & $04(100 \%)$ \\
\hline Proteus vulgaris (2) & NT & $01(50 \%)$ & $01(50 \%)$ & $02(100 \%)$ & $02(100 \%)$ & $01(50 \%)$ & $02(100 \%)$ & $02(100 \%)$ & $02(100 \%)$ & NT \\
\hline Total (52) & $\begin{array}{c}05(9.6 \\
\%)\end{array}$ & $24(46.2 \%)$ & $30(57.7 \%)$ & $37(71.2 \%)$ & $40(76.9 \%)$ & $40(76.9 \%)$ & $28(53.8 \%)$ & $29(55.8 \%)$ & $49(94.2 \%)$ & $50(96.2 \%)$ \\
\hline
\end{tabular}

\section{DISCUSSION}

The incidence of C-section is increasing, and higher rates of post CS infection have been reported from developing countries. ${ }^{11}$ Various factors influence the incidence and aetiology of post C-section infection. In the present study a total of $83(83 \%)$ cases of SSI underwent emergency caesarean section while only $17(17 \%)$ cases underwent elective caesarean section. 30 cases (30\%) had PROM. Similar findings were also reported by De D et al. ${ }^{7}$ who noted $79.3 \%$ cases were emergency while $20.7 \%$ cases were elective Caesarean section and 25.6\% cases had PROM. In our study 26
(26\%) cases of SSI had prolonged labour, 16 cases $(16 \%)$ had $\mathrm{BMI} \geq 25,9 \%$ of cases had hypertension, 15 (15\%) were found to be anaemic, 2 (2\%) were diabetic, 22 (22\%) had history of previous Caesarean section. Similar to our study Jido TA et al. ${ }^{12}$ found $29.5 \%$ had prolonged labour, $11.8 \%$ were obese with $\mathrm{BMI} \geq 25,6.8 \%$ hypertensive. Wolch C et al.13 found $19.3 \%$ patients obese. Dhar $\mathrm{H}$ et al. ${ }^{14}$ found $17.5 \%$ cases anaemic, Bengal VB et al. ${ }^{15}$ found $2 \%$ cases were diabetic. Charrier et al. ${ }^{16}$ found $35.3 \%$ cases had previous C-section.

In the present study, organisms were observed under microscope in $72 \%$ Gram stained smears while $28 \%$ smears yielded no organism. Similarly, in the study conducted by 
Kaplan NM et al. ${ }^{17} 82.2 \%$ Gram-stained smears revealed microorganisms and $17.8 \%$ smears yielded no organism.

A total of 74 cases ( $74 \%$ ) yielded positive bacterial culture and in 26 cases (26\%) culture was sterile. This finding closely corroborates with reports of positive culture of $72 \%$ of Mpogoro FJ et al. ${ }^{18}$ and Agboeze et al. ${ }^{19}$ Out of 74 culture positive 10 (13.5 \%) were polymicrobial yielding two organisms together at the same time. Similarly, $8.7 \%$ polymicrobial infection was observed by Nwankwo et al. ${ }^{11}$ $9.43 \%$ by Danso et al. ${ }^{20}$

When comparison was made between smear positive cases with culture positive cases, positive predictive value of Gram stain came out to be $97.2 \%$ when used to predict positive culture results for wound infections. This is much similar to the study done by Kaplan NM et al. ${ }^{17}$ where positive predictive value was found to be $97.7 \%$. Studies on bacteriology of post caesarean surgical site infection are few. In the present study a total of 84 isolates were obtained. Staphylococcus aureus 32 (38.1\%) was the predominant isolate. Danso KA et al. ${ }^{20}$ and Kaplan NM et al. ${ }^{17}$ also found $S$. aureus as the commonest isolate in their studies and reported it to be $41.5 \%$ and $42 \%$ respectively.

The second most common isolate in the present study was E. coli 20 out of 84 isolates (23.8\%). Similarly, Danso KA et al. ${ }^{20}$ observed $18.9 \%$ E. coli as the second commonest isolate. Klebsiella pneumoniae, in this study, constituted $16.7 \%$ of total isolates corresponding closely with that of the study by Kaplan $\mathrm{NM}$ et al. $20 \%$ and also similar to De D et al. $14.8 \%$. Next commonly isolated organism in the present study was Pseudomonas aeruginosa, which was $9.5 \%$ of total isolates. Similarly, Danso et al. isolated $7.5 \%$, Jido TA et al. ${ }^{12}$ isolated $6.8 \%$, and Dhar $\mathrm{H}$ et al. isolated $8.5 \%$ Pseudomonas aeruginosa of all isolates in their study. Both Citrobacter freundii and Acinetobacter baumannii constituted $4.76 \%$ and Proteus vulgaris $2.38 \%$ of total isolates. Similar to the present study De D et al. isolated $3.12 \%$ of Citrobacter freundii.

In the present study out of 32 isolated Staphylococcus aureus 25 (78.1\%) were methicillin-sensitive Staphylococcus aureus (MSSA) strains while 7 (21.9\%) were methicillinresistant Staphylococcus aureus (MRSA) strains. This is similar to the studies of De D et al. who reported 76.2\% MSSA strains and $23.8 \%$ MRSA strains. Also in a similar way, Nwankwo E et al. recorded $76.7 \%$ MSSA strains and $23.3 \%$ MRSA strains. The present study shows $100 \%$ sensitivity of $S$. aureus to vancomycin and linezolid; $71.9 \%$ sensitivity to ciprofloxacin (92\% MSSA and $28.6 \%$ MRSA strains) and $65.6 \%$ sensitivity to aminoglycosides (76\% MSSA and $28.6 \%$ MRSA strains) similar to other studies De D et al. and Nwankwo E et al.

The in vitro susceptibility test of the bacterial isolates revealed that polymyxin B at $96.2 \%$ sensitivity was the most effective antimicrobial agent against the entire spectrum of the Gram-negative bacilli isolated. It was followed by imipenem $94.2 \%$ and gentamycin $76.9 \%$. E. coli showed $100 \%$ sensitivity to polymyxin $\mathrm{B}$ and imipenem, followed by ciprofloxacin $90 \%$. This finding co-relates with the studies of De D et al. Danso KA et al. Nwankwo E et al. and Ranjan KP et al. ${ }^{21}$

\section{CONCLUSIONS}

Post Caesarean wound infection constitutes a serious maternal health concern. Significant number of cases of emergency caesarean, premature rupture of membranes, prolong labour, previous $\mathrm{C}$-section and anaemia were seen to develop SSI.

With the emergence of drug resistance and MRSA strains in our scenario it is important to go for bacterial culture which will provide identification of causative organism and determine antimicrobial susceptibility which will help combat the problem. The finding of preponderance of Staphylococcus aureus and Gram negative bacilli in this study with good antibiotic sensitivity against the fluoroquinolone and aminoglycosides is of local clinical relevance.

Staphylococcus aureus is often found living on the skin and in the nose, therefore, it is important to implement regular handwashing, avoid cross infection by restricting visitors and routine education regarding infection control measures has to be provided to health workers.

Data sharing statement provided by the authors is available with the full text of this article at jemds.com.

Financial or other competing interests: None.

Disclosure forms provided by the authors are available with the full text of this article at jemds.com.

\section{REFERENCES}

[1] Cunningham F, Leveno K, Bloom S, et al. Cesarean delivery and peripartum hysterectomy. Williams Obstetrics. $24^{\text {th }}$ edn. McGraw-Hill 2014: p. 587-608.

[2] Curtin SC, Gregory KD, Korst LM, et al. Maternal morbidity for vaginal and cesarean deliveries, according to previous Cesarean history: new data from the birth certificate, 2013. Natl Vital Stat Rep 2015;64(4):1-13.

[3] Patel AJ, Velani SP. Study of wound infection: major morbidity after caesarean section. Global Journal for Research Analysis 2014;3(7).

[4] Rosenberg K. Preprocedure antibiotics reduce infection after caesarean delivery. Am J Nursing 2012;112(11):14.

[5] Mangram AJ, Horan TC, Pearson ML, et al. Guideline for prevention of surgical site infection, 1999. Hospital infection control practices advisory committee. Infect Control Hosp Epidemiol 1999;20(4):250-78.

[6] Weigelt JA, Lipsky BA, Tabak YP, et al. Surgical site infections: causative pathogens \& associated outcomes. Am J Infect Control 2010;38(2):112-20.

[7] De D, Saxena S, Mehta G, et al. Risk factor analysis \& microbial etiology of surgical site infections following lower segment caesarean section. International Journal of Antibiotics 2013;10:1-6.

[8] Cunningham FG, Vandorsten JP. Operative Obstetrics. $2^{\text {nd }}$ edn. New York: McGraw-Hill Publication 2002.

[9] Anderson DJ, Sexton DJ, Kanafani ZA, et al. Severe surgical site infection in community hospitals: epidemiology, key procedures and the changing prevalence of methicillinresistant staphylococcus aureus. Infect Control Hosp Epidemiol 2007;28(9):1047-53.

[10] Clinical and Laboratory Standards Institute. Performance standards for antimicrobial susceptibility testing. Twenty third information supplement M100-S23. Wayne, PA: Clinical and Laboratory Standards Institute 2013.

[11] Nwankwo E, Shuaibu S. Bacteriology of post caesarean wound infection in a specialist hospital in Kano, North 
Western Nigeria. Sierra Leone Journal of Biomedical Research 2013;5(1):15-22.

[12] Jido T, Garba I. Surgical-site infection following cesarean section in Kano, Nigeria. Ann Med Health Sci Res 2012;2(1):33-6.

[13] Wloch C, Wilson J, Lamagni $\mathrm{T}$, et al. Risk factors for surgical site infection following caesarean section in England: results from a multicentre cohort study. BJOG 2012;119(11):1324-33.

[14] Dhar H, Busaidi I, Rathi B, et al. A study of post caesarean section wound infections in a regional referral hospital, Oman. Sultan Qaboos Univ Med J 2014;14(2):211-7.

[15] Bangal VB, Borawake SK, Shinde KK, et al. Study of surgical site infections following gynaecological surgery at tertiary care teaching hospital in rural India. Int J Biomed Res 2014;5(2):113.

[16] Charrier L, Serafini P, Ribatti A, et al. Post-partum surgical wound infections : incidence after caesarean section in an Italian hospital. Journal of Preventive Medicine and Hygiene 2009;50(3):159-63.
[17] Kaplan NM, Smadi AA, Al-Taani MI, et al. Microbiology of wound infection after caesarean section in a Jordanian hospital. East Mediterr Health J 2003;9(5-6):1068-74.

[18] Mpogoro FJ, Mshana SE, Mirambo MM, et al. Incidence and predictors of surgical site infections following caesarean sections at Bugando Medical Centre, Mwanza, Tanzania. Antimicrob Resist Infect Control 2014;3:25.

[19] Agboeze J, Onoh R, Umeora OU, et al. Microbiological pattern of postcesarean wound infection at federal teaching hospital, Abakaliki. African Journal of Medical and Health Sciences 2013;12(2):99-102.

[20] Danso KA, Adu-Sarkodie Y. Abdominal wound infection complicating cesarean sections. Ghana Medical Journal 1998;32b:1003-8.

[21] Ranjan KP, Ranjan N, Bansal SK, et al. Prevalence of Pseudomonas aeruginosa in post-operative wound infection in a referral hospital in Haryana, India. J Lab Physicians 2010;2(2):74-7. 